\title{
Soils of Eagle Crater and Meridiani Planum at the Opportunity Rover Landing Site
}

\begin{abstract}
The soils at the Opportunity site are fine-grained basaltic sands mixed with dust and sulfate-rich outcrop debris. Hematite is concentrated in spherules eroded from the strata. Ongoing saltation exhumes the spherules and their fragments, concentrating them at the surface. Spherules emerge from soils coated, perhaps from subsurface cementation, by salts. Two types of vesicular clasts may represent basaltic sand sources. Eolian ripples, armored by well-sorted hematite-rich grains, pervade Meridiani Planum. The thickness of the soil on the plain is estimated to be about a meter. The flatness and thin cover suggest that the plain may represent the original sedimentary surface.
\end{abstract}

L. A. Soderblom, ${ }^{1 *}$ R. C. Anderson, ${ }^{2}$ R. E. Arvidson, ${ }^{3}$ J. F. Bell III, ${ }^{4}$ N. A. Cabrol, ${ }^{5}$ W. Calvin, ${ }^{6}$ P. R. Christensen, ${ }^{7}$ B. C. Clark, ${ }^{8}$ T. Economou, ${ }^{9}$ B. L. Ehlmann, ${ }^{3}$ W. H. Farrand, ${ }^{10}$ D. Fike, ${ }^{11}$ R. Gellert, ${ }^{12}$ T. D. Glotch, ${ }^{7}$ M. P. Golombek, ${ }^{2}$ R. Greeley, ${ }^{7}$ J. P. Grotzinger, ${ }^{11}$ K. E. Herkenhoff, ${ }^{1}$ D. J. Jerolmack, ${ }^{11}$ J. R. Johnson, ${ }^{1}$ B. Jolliff, ${ }^{3}$ G. Klingelhöfer, ${ }^{13}$ A. H. Knoll, ${ }^{14}$ Z. A. Learner, ${ }^{4}$ R. Li, ${ }^{15}$ M. C. Malin, ${ }^{16}$ S. M. McLennan, ${ }^{17}$ H. Y. McSween, ${ }^{18}$ D. W. Ming, ${ }^{19}$ R. V. Morris, ${ }^{19}$ J. W. Rice Jr., ${ }^{7}$ L. Richter, ${ }^{20}$ R. Rieder, ${ }^{12}$ D. Rodionov, ${ }^{13}$ C. Schröder, ${ }^{13}$ F. P. Seelos IV, ${ }^{3}$ J. M. Soderblom, ${ }^{4}$ S. W. Squyres, ${ }^{4}$ R. Sullivan, ${ }^{4}$ W. A. Watters, ${ }^{11}$ C. M. Weitz, ${ }^{21}$ M. B. Wyatt, ${ }^{7}$ A. Yen, ${ }^{2}$ J. Zipfel ${ }^{12}$

Martian soils (1) are remnants of their source rocks and thus provide insight into geologic processes and history on local, regional, and global scales. Whether soils are actively changing or represent static records of past climates is a key question for Mars. The soils of Meridiani Planum, where Opportunity landed, contrast with soils at sites visited by the Viking Landers, Mars Pathfinder, and Spirit. The regional albedo of Meridiani Planum is $\sim 0.12$, among the lowest on Mars (2, 3). Mars Global Surveyor (MGS) Mars

${ }^{1}$ U.S. Geological Survey, Flagstaff, AZ 86001, USA. ${ }^{2}$ Jet Propulsion Laboratory, Caltech, Pasadena, CA 91109, USA. ${ }^{3}$ Department of Earth and Planetary Sciences, Washington University, St. Louis, MO 63130, USA. ${ }^{4}$ Department of Astronomy, Cornell University, Ithaca, NY 14853, USA. ${ }^{5}$ NASA Ames/ SETI Institute, Moffett Field, CA 94035, USA. ${ }^{6}$ University of Nevada, Reno, Geological Sciences, Reno, NV 89557, USA. ${ }^{7}$ Department of Geological Sciences, Arizona State University, Tempe, AZ 85287-1404, USA. ${ }^{8}$ Lockheed Martin Corporation, Littleton, CO 80127, USA. ${ }^{9}$ Enrico Fermi Institute, University of Chicago, Chicago, IL 60637, USA. ${ }^{10}$ Space Science Institute, Boulder, CO 80301, USA. ${ }^{11}$ Massachusetts Institute of Technology, Earth, Atmospheric and Planetary Sciences, Cambridge, MA 02139, USA. ${ }^{12}$ Max Planck Institut für Chemie, Kosmochemie, Mainz, Germany. ${ }^{13}$ Johannes Gutenberg-University, Mainz, Germany. ${ }^{14}$ Botanical Museum, Harvard University, Cambridge, MA 02138, USA. ${ }^{15}$ Department of Civil and Environmental Engineering and Geodetic Science, Ohio State University, Columbus, $\mathrm{OH} 43210$ USA. ${ }^{16}$ Malin Space Science Systems, San Diego, CA 92191, USA. ${ }^{17}$ Department of Geosciences, State University of New York at Stony Brook, Stony Brook, NY 11794, USA. ${ }^{18}$ Department of Earth and Planetary Sciences, University of Tennessee, Knoxville, TN 37996, USA. ${ }^{19}$ NASA Johnson Space Center, Houston, TX 77058, USA. ${ }^{20}$ DLR Institute of Space Simulation, D-51147, Cologne, Germany. ${ }^{21}$ Planetary Science Institute, Tucson, AZ 85719, USA.

*To whom correspondence should be addressed. E-mail: Isoderblom@usgs.gov
Orbiter Camera (MOC) images (4) show that the floors of the sparse impact craters, such as Eagle and Endurance (5), are slightly darker than the surrounding plains. Some observers have suspected that these dark crater floors represent active, saltating dark sand deposits $(6,7)$. Meridiani Planum is also unique in its orbital signature; the MGS Thermal Emission Spectrometer showed the strongest, most extensive signature for coarsely crystalline hematite of any region on the planet (8). Because most modes of hematite formation involve liquid water, Meridiani Planum is a prime site for exploration. Understanding the nature of its unusual soils, confirming the existence and understanding the nature of occurrence of hematite, and relating these to the regional geologic history are key objectives of Opportunity's mission and are the subject of this report.

During landing, Opportunity bounced $\sim 26$ times, traveled $\sim 300 \mathrm{~m}$ across Meridiani Planum, and finally came to rest inside $20-\mathrm{m}$ diameter Eagle crater. The airbags remained clean (Plate 1), unlike those of Pathfinder and Spirit, which were stained with reddish dust $(9,10)$. Evidently the Meridiani surface is less dusty, presumably because of ongoing deflation by wind, stripping away dust left by annual global storms. Airbag bounce marks on the crater floor indicate that deflation leaves a thin, dark lag deposit that is easily depressed into the brighter, redder subsurface soil. Two crater-floor trenches show brighter materials just below the surface (Plates 14 and 16). Panoramic Camera (Pancam) images show the $750-\mathrm{nm}$ albedo of the surface to be $\sim 30 \%$ darker than that of the trench floor (Plate 14). Other landing sites usually show the reverse; in general, the surface is brighter than the subsurface when exposed by tracks and trenches $(9,11)$.

Pancam images, Miniature Thermal Emission Spectrometer (Mini-TES), Mössbauer Spectrometer (MB), and Alpha Particle XRay Spectrometer (APXS) data for the relatively dust-free, dark sand surface at Tarmac, a soil site reached soon after Opportunity's egress, show that the composition and mineralogy of an olivine-bearing basalt with $\sim 10 \%$ of the $\mathrm{Fe}$ is in the form of hematite $(3,12-14)$. Microscopic Imager (MI) images show that this dark surface sand is finer than $\sim 150 \mu \mathrm{m}$ (15). The grain size expected to be most easily moved by saltation on Mars is $\sim 100 \mu \mathrm{m}$ (16). Pancam images show well-developed eolian saltation impact ripples of varying wavelengths across the crater floor. The lower limit of the sand grain size is unknown, owing to the MI resolution (pixel size $\sim 30 \mu \mathrm{m}$ ). However, we suspect the sand to be well sorted roughly in the size range 50 to $150 \mu \mathrm{m}$, because the bulk of the grains are resolvable in the MI images ( 2 to 5 pixels) and most of the sparse sand grains lying silhouetted on the brighter outcrop are resolvable (15).

The low albedo of the surface soils in Eagle crater shows it to be relatively dustfree. Further, when pressed into the Tarmac sand, the MB footprint exhibited poorly defined margins, as would be expected for cohesionless sand-sized particles. No compaction was apparent; the fine-grained sand simply flowed around coarser clasts (15). By contrast, when the MB was pressed into the bright, reddish floors of the trenches, the materials were compacted with well-preserved imprints, as expected for cohesive silt- to clay-sized particles $(15,17)$. It is our interpretation that the surface of the crater floor is covered by a deposit of actively moving, fine-grained dark sand that is least dusty and darkest at its surface and increases in dust content below the surface. Trench walls in the Eagle crater floor exhibit some clods and clumps, suggesting very weak cohesion, although any cementation is 
weaker than that found at other landing sites and on Meridiani Planum $(11,17,18)$.

Before Opportunity drove off the lander, Mini-TES mapped the abundance of hematite across the floor and rim of Eagle crater and out onto the Meridiani plain (Plate 3 and Fig. 1) (12). The hematite abundance the crater floor, increases toward the crater rim and out onto the plain, and is lowest in the bounce marks. The visible-near-infrared reflectance spectrum of fine-grained hematite (as well as many $\mathrm{Fe}^{3+}$ minerals) shows a broad absorption feature with a minimum near $0.9 \mu \mathrm{m}$ and a rapid increase in reflectance toward $1.0 \mu \mathrm{m}$ (3). A ratio of Pancam images at $1.00 \mu \mathrm{m}$ and $0.93 \mu \mathrm{m}$ shows a pattern consistent with Mini-TES measurements between the hematite-poor bounce marks and undisturbed soil (Fig. 1B). Evidently the hematite occurs in a thin surface lag that is

\section{A}

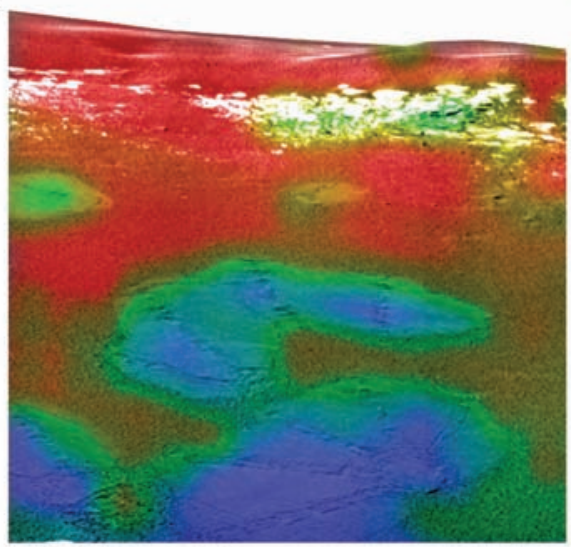
decreases from northwest to southeast across

easily pushed into the hematite-poor soils. Ultimately the Mini-TES hematite signature was traced by MB and APXS (12-14) to the ubiquitous spherules on Meridiani Planum believed to be have been formed as concretions in the outcrop during diagenesis (19).

Global circulation models (20) and bright wind streaks seen in MOC and descent images indicate that the current prevailing wind direction is to the southeast. The Opportunity Ledge outcrop is centered in the northwest wall of Eagle crater (19); we infer that it is being exposed by wind deflation, the fine-grained basaltic sand that buries the outcrop being stripped off and deposited on the crater floor and opposite wall. This sand deposit terminates on the downwind crater rim in a large sinuous crested eolian bedform (Plate 2). Its sharp crest and steep outward slope $\left(\sim 30^{\circ}\right)$ suggest a dune slip face. Also visible in Plate 2 are bright dust deposits in

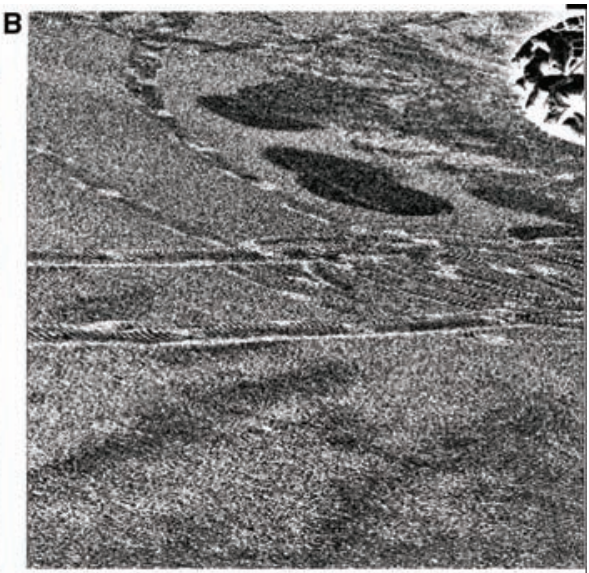

Fig. 1. (A) Mini-TES map of hematite abundance for a section of the floor of Eagle crater near the lander acquired before egress (red, high; blue, low). (B) Pancam ratio image of bounce marks acquired from the south rim of Eagle crater (sol 60) using images acquired for two near-infrared bands (R7/R6; central $\lambda$ : $1001 \mathrm{~nm}$ and $933 \mathrm{~nm}$ ). Bounce marks are roughly a meter in diameter.

Fig. 2. Pancam-enhanced natural color image (RGB: L2, L5, L7; central $\lambda$ : $753 \mathrm{~nm}, 535 \mathrm{~nm}$, and $440 \mathrm{~nm}$ ) of ubiquitous small crested bedforms of Meridiani Planum at Anatolia (sol 71). The foreground width of the image is $\sim 2 \mathrm{~m}$.

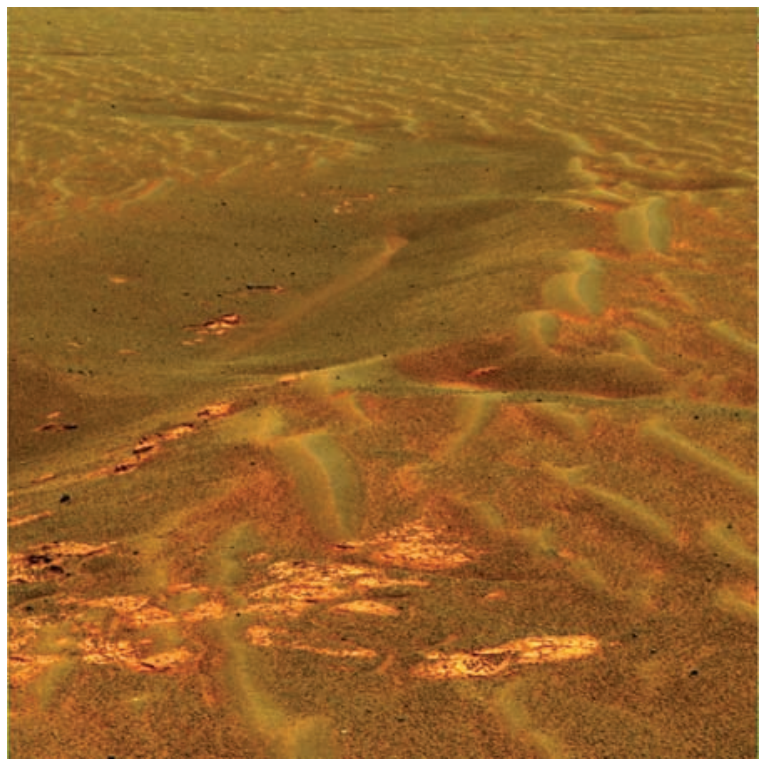

the lee of the crest. These represent the thickest local accumulations of bright dust found at the Meridiani site.

During sols 60 to $90(21)$, Opportunity drove $\sim 570 \mathrm{~m}$ to the east across Meridiani Planum toward Endurance crater (22). In contrast to the floor of Eagle crater, the flat plain is characterized by ubiquitous small sinuous crested eolian bedforms (Plate 2 and Fig. 2) and intervening troughs. These crested forms are $\sim 10 \mathrm{~cm}$ wide, meters long, and 1 to $2 \mathrm{~cm}$ high; the spacing between ripple crests is tens of centimeters. Such forms also occur on the northern and western inner walls of Eagle crater where they lap over the rim from the plains (Plates 1 and 2). Using its front wheels, Opportunity dug a trench through one of these bedforms on sol 73 (17). MI and Pancam images of the Ripple-X trench wall cut through the crest (17) show none of the internal stratification that might be expected for small active dunes. The bedforms are similar to granule-armored eolian ripples studied by Spirit in Gusev crater $(11,23,24)$. In both cases, the crests are armored with well-sorted millimetersized rounded granules that overlie finegrained sand and dust. These granules appear to form as millimeter-sized grains, driven across the surface by creep induced by the impact of saltating sand-sized particles or rolled directly by the wind, pile up, and migrate in sinuous swaths. The resulting armor impedes removal of the subjacent sand. Thus, as saltating sands move through the system, fine-grained particles are continuously removed from adjacent troughs, leaving elevated, armored ripple crests.

Pancam images of the MI-accessible targets can be acquired from as close as $\sim 1.5 \mathrm{~m}$ with pixel spacing of $\sim 0.4 \mathrm{~mm}$. Although the limiting Pancam optical resolution is $\sim 1 \mathrm{~mm} \mathrm{(3),} \mathrm{these} \mathrm{oversampled}$ images provide high signal-to-noise for multispectral analysis of the clasts. By merging the Pancam spectral cubes with the higher resolution $(30 \mu \mathrm{m} /$ pixel) MI images, composite image cubes are made that permit correlation of spectral classes with the morphologies of individual clasts (Fig. 3). Even with some exaggeration of the natural color (Fig. 3B), variation among the clasts is difficult to distinguish. By including the nearinfrared bands $(0.8$ to $1.0 \mu \mathrm{m})$, the spectral variations are more apparent (Fig. 3C).

Several types of soil clasts can be identified at the Chocolate Chip soil site near the center of the Eagle crater floor (Fig. $3)$. In addition to the spherules that are yellow, orange, and purple in the nearinfrared color composites, two other types of lithic fragments, most likely basalt clasts, are also evident (blue and green in Fig. 3C). They exhibit vesicles, are irregular in shape, and have rounded edges, presumably owing 
to abrasion by basaltic sand. There may be two different basaltic sources. Although most are 3 to $5 \mathrm{~mm}$ in diameter, spherule diameters are 0.6 to $6 \mathrm{~mm}$ (15). Most lithic fragments are 1 to $3 \mathrm{~mm}$ in size, although $\mathrm{cm}$-sized cobbles, possibly of basaltic composition, are scattered in Eagle crater.

At the Chocolate Chip site, the spherules exhibit a correlation between their spectral reflectance and their depth of burial in the soil (Fig. 3). Our interpretation is as follows. As they are exposed by wind deflation, spherules emerge coated with brighter material. The coatings have been abraded from the spherules that have fully emerged and are now perched on the surface. These are darkest and least red in their overall spectra (their actual color would be gray) (3) and exhibit the strongest broad $\mathrm{Fe}^{3+}$ absorption band centered at $0.9 \mu \mathrm{m}$ (Fig. 3D). A few that are broken exhibit the same spectra in their interiors, leading to the conclusion that the darker, perched spherules are uncoated. Spherules that are still about half buried show this absorption band weakly in their centers, where the path length through a thin coating would be minimized. The most deeply buried and heavily coated spherules (bright yellow in Fig. 3, A and C) show a rougher texture; in most cases, dark grains (presumably basalt) are visible in or on the coatings. The spectral reflectance of these thick coatings is similar to that of bright martian dust and to the Eagle crater sulfaterich outcrop materials. Some bright granules probably are outcrop fragments.

A possible explanation for the origin of the coatings involves formation while spherules reside in the uppermost few millimeters of the soil, where salts interact with low-level moisture that interchanges diurnally between the surface and atmosphere (25). Alternatively, the coatings may be remnants of sulfate-rich outcrop material still adhering to spherules. Most spherules found at the base of the outcrop are uncoated. However, these may not have been derived from local outcrop but rather may have been transported from the adjacent plains down-slope into the crater (12).

Pancam multispectral images of the Eagle crater soil clasts (e.g., Fig. 3) exhibit greater variability in reflectance $(0.4$ to $1.0 \mu \mathrm{m})$ of lithologic materials than previously observed in data collected from the surface, from orbit, or from Earth (3). Abrasion of the surfaces in Eagle crater by actively saltating, fine-grained sand, coupled with the diverse collection of materials, both derived locally and carried into the crater by wind and impact, accounts for the observed spectral diversity. This abrasion may enhance the TES orbital hematite signature (8). Many spherules show pitted surfaces; others are smooth, suggesting variable exposure to the abrasive eolian environment.
MI images of the troughs between the pervasive ripples on the Meridiani plains (Fig. 2) reveal that most of the clasts are spherules (Fig. 4A) whose Pancam spectra are the same as those of the uncoated spherules found in Eagle crater. Compared to the crater floor, the plains exhibit a greater abundance of bright red material, likely siltsized or finer dust and sulfate-rich outcrop material. MB imprints in the ripple crests show that the grains are cemented by a surface crust of this bright red material (15). Vesicular fragments like those on Eagle crater floor are rare. Mixed with the hematitic spherules in the troughs are smaller fragments that exhibit the same Pancam spectrum as the spherules (3). This, coupled with the arcuate edges of a few of the fragments, suggests that they are broken spherules. Figure 4B shows the densely packed population of rounded and sorted spherule fragments that armor the ripples in Meridiani Planum. A combination of MiniTES, MB, and APXS data confirms that these rounded granules are hematitic (12-14). Indeed, because of the small contribution of basaltic sand on the crests, MB data for these armors or pavements show the highest measured concentration of hematite (14). The grains are well sorted with a mean diameter of $\sim 1 \mathrm{~mm}$ (SD $\sim 0.3 \mathrm{~mm}$ ). The coarse basaltic sand grains that armor the ripples on the Gusev plains have mean diameters of $\sim 1.8 \mathrm{~mm}$ (24). The smaller mean diameter at Meridiani could be related to higher specific gravity of the hematitic grains or to higher threshold wind speeds.

Trends in compositional variations can help to elucidate the sources of the soils. The elemental composition of Meridiani soils, as measured by APXS, is quite close to the results for previous sites (13), although soil compositions from the different sites differ in detail (Fig. 5) (26-30). Whereas Meridiani soils lie atop a sulfaterich evaporite deposit, they exhibit the lowest average $\mathrm{S}$ concentrations of all sites. Fe enrichment trends toward the
Fig. 3. Merge of $\mathrm{MI}$ and 13-filter Pancam images of Chocolate Chip soil target on the floor of Eagle crater from sol 54. (A) Pancam visible-nearinfrared false-color image (RGB: filters R7, R2, R1; central $\lambda$ : $1001 \mathrm{~nm}, 750 \mathrm{~nm}$, and $440 \mathrm{~nm}$ ). Ml footprint shown in red is $3 \mathrm{~cm}$ wide. (B) Enhanced natural-color MI-Pancam merged image (RGB: filters L2, L5, L7; central $\lambda: 750 \mathrm{~nm}, 535$ $\mathrm{nm}$, and $440 \mathrm{~nm}$; image width $3 \mathrm{~cm}$ ). (C) Visible-near-infrared false-color MI-Pancam merged image (RGB: filters R7, R2, R1; image width $3 \mathrm{~cm}$ ). (D) Spectral reflectance of selected clasts.

Fig. 4. Merge of $\mathrm{MI}$ and 13-filter Pancam images of typical Meridiani Planum ripple and trough acquired on sol 73. (A) Enhanced natural-color MI-Pancam merged image of inter-ripple trough (RGB: filters $L 2, L 5, L 7$; central $\lambda$ : $753 \mathrm{~nm}, 535 \mathrm{~nm}$, and $440 \mathrm{~nm}$; image width $3 \mathrm{~cm}$ ). (B) Same MIPancam image version of ripple crest [color filters and processing as in (A); image width $3 \mathrm{~cm}$ ].
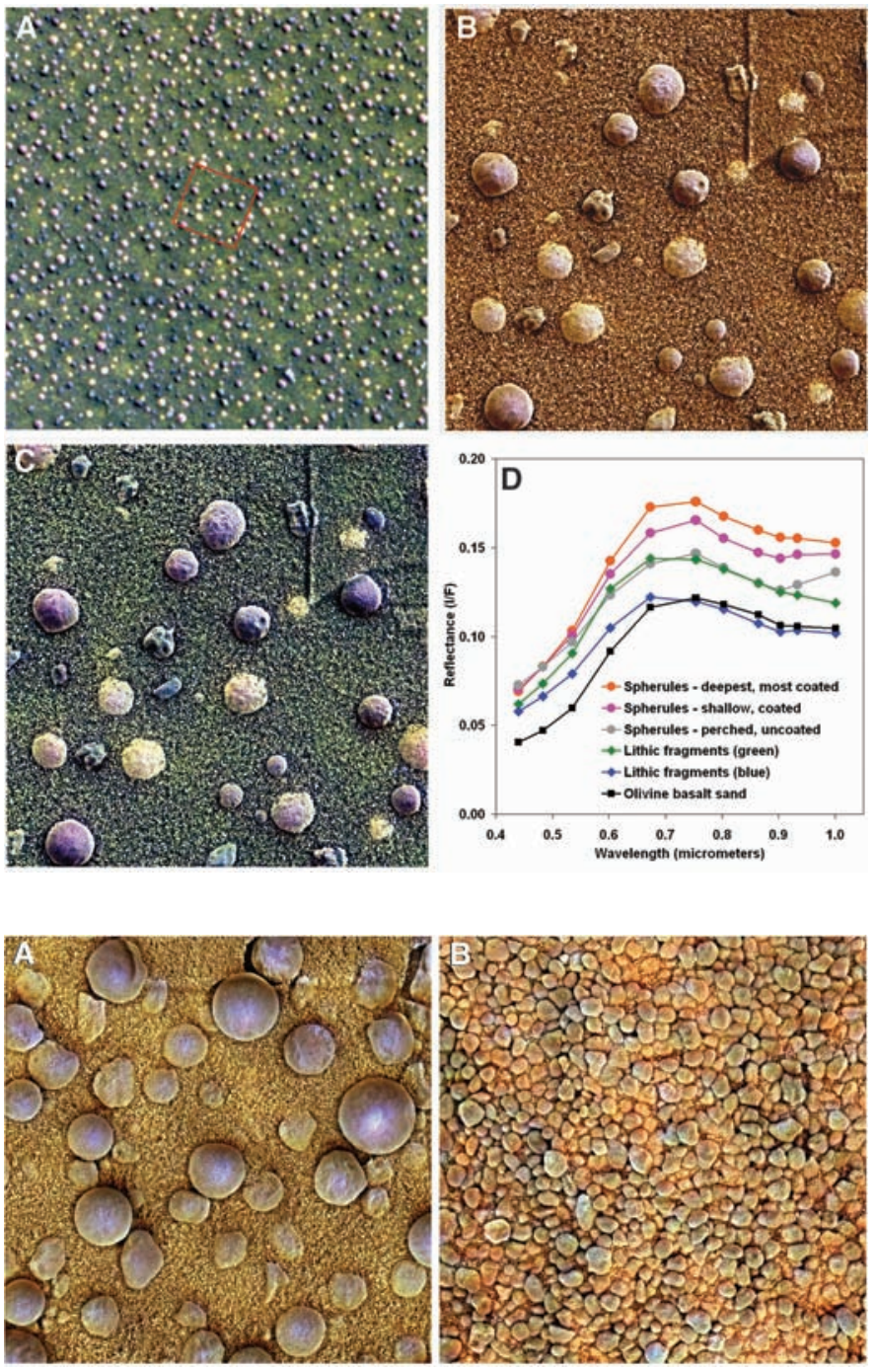

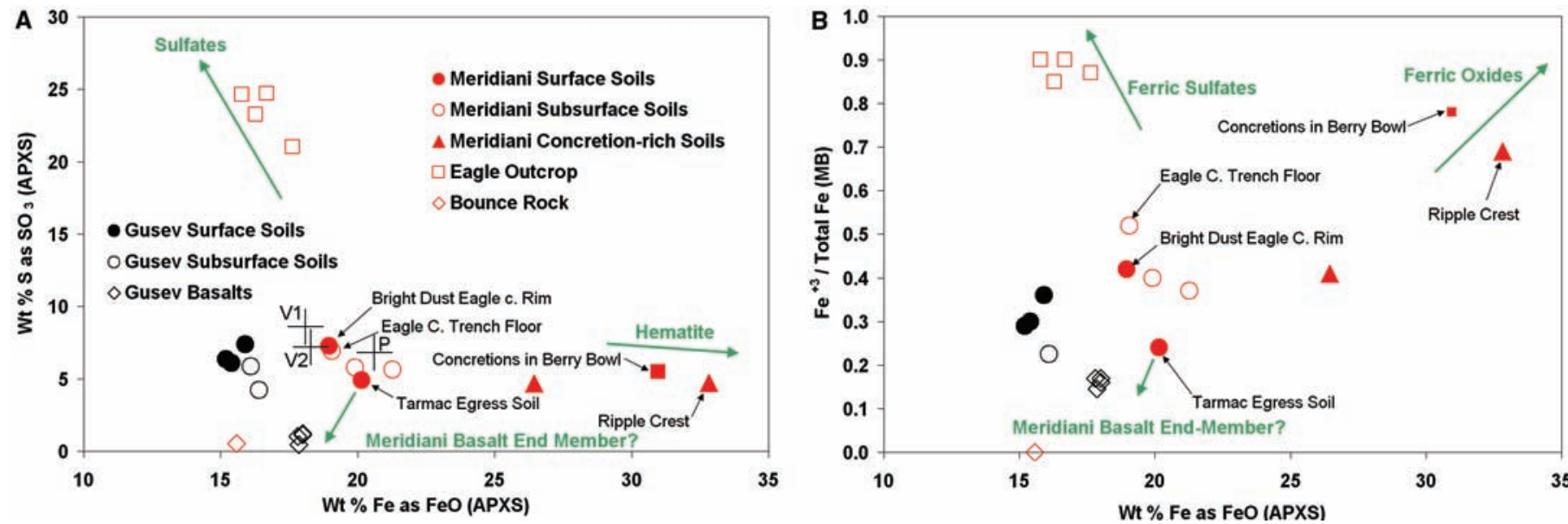

Fig. 5. Trends in sulfate (A) and iron-oxidation state (B) among Meridiani soils and local sources materials. Shown for comparison are Gusev soils and rocks and average soil from the Viking 1 and 2 and Pathfinder sites. Green arrows are schematic and denote compositional end members that constitute the Meridiani soils.

hematite-rich soils, consistent with the occurrence and abundance of ferric-ironrich spherules as components in the soils. Apart from those that exhibit $\mathrm{Fe}^{3+}$ enrichment, Meridiani soil compositions cluster near Pathfinder and Viking soils. Two of the Meridiani soils with highest $\mathrm{SO}_{3}$ content (Fig. 5A) are among the most oxidized of the spherule-poor soils (Fig. 5B). These may be the best candidates for airborne dust. The higher $\mathrm{Fe}$ in Meridiani soils cannot be explained by igneous rocks of the class of Bounce rock (22) nor of the bulk matrix in the outcrop. However, admixture of weathered-out hematite spherules and their fragments could increase the $\mathrm{Fe}$ in this soil to the observed composition. Abundances of sulfates in Meridiani soils are lower than those found in outcrop materials by a factor of 4 to 5 , consistent with erosion of these weak rocks with near complete removal of the outcrop debris by active eolian activity.

Soils must dominate Meridiani Planum's regional signatures of basalt and hematite observed from orbit. The hematite signature is imparted by hematitic spherules and their fragments eroded from sulfate-rich evaporite rocks. The source of the basalt sand remains unknown. Although Eagle crater sand is dominantly olivine-bearing basalt, MB data show that $\sim 10 \%$ of the Fe in the Tarmac soil is in the form of hematite (14). A model composition for the Meridiani basalt suggests a slightly higher $\mathrm{FeO}$ concentration than for the Gusev basalts. The Fe-poor Bounce rock pyroxene-rich basalt $(3,12-14,22)$ is not the source of the basaltic sand. One or both of the vesicular clasts (blue and green in Fig. 3) could be examples of the source lithology. If so, the vesicular grains suggest that the source may have been a coherent basaltic rock rather than volcanic ash. The ejecta of Eagle, Fram, and 170-m-diameter Endurance craters (Opportunity was $\sim 200 \mathrm{~m}$ from
Endurance on sol 90) do not show strewn fields of basalt that should have been excavated from depth if there were a competent basaltic unit in the near subsurface. The many dark cobbles on the plain and in Eagle crater could, like Bounce rock (22), be impact erratics and may not represent the local source. If basaltic sand is not locally derived, it could have been transported by saltation from adjacent regions. Grains from a coherent basaltic rock could survive transport over hundreds of kilometers (20).

On the traverse to Endurance crater, outcrops were observed at shallow depths: outside the rim of Eagle crater, near the linear troughs [possibly a fracture system (22)] at Anatolia (Fig. 2), and at Fram crater (Plate 4) located on a regional rise (17). Soil often is thinly draped over underlying blocks of outcrop. Thus, the soils on the plains are probably only on the order of a meter thick. The concentration of spherules in the Eagle crater outcrop is roughly 1 to $2 \%$ by volume (19). Given that the spherules are concentrated at the surface, being sparse in trenches, the spherules may comprise a layer no more than a centimeter thick. This would suggest that the amount of eroded sulfate-rich strata needed to generate the observed spherules would be a few meters at most. The flat nature of the Meridiani Planum is striking; nowhere do we see erosional remnants (mesas or hillocks) of stratigraphically higher units. It also seems unlikely that most of the spherules have been transported out of the region or destroyed by mechanical erosion. Taken together, these observations suggest that the current plains surface is approximately at the top of the original evaporite stratigraphic sequence.

\section{References and Notes}

1. The term "soil" is used here to denote any loose, unconsolidated materials that can be distinguished from rocks, bedrock, or strongly cohesive sediments.
No implication for the presence or absence of organic materials or living matter is intended.

2. M. P. Golombek et al., J. Geophys. Res. 108, 8072 (2003).

3. J. E. Bell III et al., Science 306, 1703 (2004)

4. MOC image R0802184 was radiometrically calibrated using the ISIS (Integrated Software for Imagers and Spectrometers) available from the Astrogeology Team (http://isis.astrogeology.usgs.gov/lsis2/isis-bin/ isis.cgi) of the U.S. Geological Survey in Flagstaff, $\mathrm{AZ}$.

5. Names have been assigned to geographic features by the Mars Exploration Rover (MER) team for planning and operations purposes. The names are not formally recognized by the International Astronomical Union.

6. P. R. Christensen, J. Geophys. Res. 93, 7611 (1988).

7. M. C. Malin, K. S. Edgett, J. Geophys. Res. 106, 23429 (1988)

8. P. R. Christensen, et al., J. Geophys. Res. 105, 9623 (2000).

9. M. P. Golombek, et al., J. Geophys. Res. 104, 8523 (2000)

10. S. W. Squyres et al., Science 305, 794 (2004).

11. R. E. Arvidson et al., Science 305, 821 (2004)

12. P. R. Christensen et al., Science 306, 1733 (2004).

13. R. Rieder et al., Science 306, 1746 (2004).

14. G. Klingelhöfer et al., Science 306, 1740 (2004).

15. K. E. Herkenhoff et al., Science 306, 1727 (2004).

16. R. Greeley et al., Geophys. Res. Lett. 7, 121 (1980).

17. R. E. Arvidson et al., Science 306, 1730 (2004).

18. H. J. Moore et al., J. Geophys. Res. 82, 4497 (1977).

19. S. W. Squyres et al., Science 306, 1709 (2004).

20. R. Greeley, S. Thompson, J. Geophys. Res. 108, 8093 (2003).

21. A martian solar day has a mean period of 24 hours $39 \mathrm{~min} 35.244 \mathrm{~s}$ and is referred to as a sol to distinguish this from a roughly $3 \%$ shorter solar day on Earth.

22. S. W. Squyres et al., Science 306, 1698 (2004).

23. R. P. Sharp, J. Geol. 71, 617 (1963).

24. R. Greeley et al., Science 305, 810 (2004).

25. B. C. Clark, D. C. Van Hart, Icarus 45, 370 (1981).

26. R. V. Morris et al., Science 305, 833 (2004).

27. R. Gellert et al., Science 305, 829 (2004).

28. B. C. Clark et al., J. Geophys. Res. 87, 10059 (1982)

29. H. Wänke et al., Space Sci. Rev. 96, 317 (2001).

30. J. Brückner et al., J. Geophys. Res. 108, 8094 (2003).

31. The research described in this paper was partially carried out at the Jet Propulsion Laboratory, California Institute of Technology, under a contract with NASA.

\section{Plates Referenced in Article}

www.sciencemag.org/cgi/content/full/306/5702/1723/ DC1

Plates $1,2,3,4,14,16$

10 September 2004; accepted 28 October 2004 
If you wish to distribute this article to others, you can order high-quality copies for your colleagues, clients, or customers by clicking here.

Permission to republish or repurpose articles or portions of articles can be obtained by following the guidelines here.

The following resources related to this article are available online at www.sciencemag.org (this information is current as of October 12, 2015 ):

Updated information and services, including high-resolution figures, can be found in the online version of this article at:

http://www.sciencemag.org/content/306/5702/1723.full.html

Supporting Online Material can be found at:

http://www.sciencemag.org/content/suppl/2004/11/30/306.5702.1723.DC1.html

A list of selected additional articles on the Science Web sites related to this article can be found at:

http://www.sciencemag.org/content/306/5702/1723.full.html\#related

This article cites 26 articles, 13 of which can be accessed free:

http://www.sciencemag.org/content/306/5702/1723.full.html\#ref-list-1

This article has been cited by 62 article(s) on the ISI Web of Science

This article has been cited by 11 articles hosted by HighWire Press; see:

http://www.sciencemag.org/content/306/5702/1723.full.html\#related-urls

This article appears in the following subject collections:

Planetary Science

http://www.sciencemag.org/cgi/collection/planet_sci 